\title{
Variational Iteration Method for Solving Boundary Value Problems of Fractional Order
}

\author{
Fadhel S. Fadhel ${ }^{(1)}$ and Saif Al - Deen M. Jameel ${ }^{(2)}$ \\ ${ }^{(1)} \mathrm{Al}$ - Nahrain University, College of Sciencel, Department of Mathematics and \\ Computer Application, Iraq \\ (Emal: fsf@sc.nahrainuniv.edu.iq,dr_fadhel67@yahoo.com) \\ ${ }^{(2)}$ Middle Technical University, Institiute of Adminstration Al - Rusaffa, Iraq \\ (Emal: saif_Aldeen2001@yahoo.com)
}

\begin{abstract}
This paper presents an approximate solution of ordinary boundary value problems using the variational iteration method. The fractional derivatives are described in the Caputo sense, because it allows traditional initial and boundary conditions to be included in the formulation of the problem. The solutions of proposed fractional equations are calculated in the form of convergent series with easily computable components. Also, we construct the variational iteration formula and its convergence to the exact solution for solving system of fractional order differential equations. Some examples are solved as an illustration to the method, in order to show the accuracy of the method and comparison with results the exact solution for the given test problems, which are given for comparison purpose. [DOI: 10.22401/ANJS.00.2.09]
\end{abstract}

Keywords: Fractional order boundary value problems, Fradctional differential equations, variational iteration method.

\section{Introduction}

Variational iteration method (VIM) which was proposed by [He, 2007] and has been recently and intensively studied by several scientists and engineers that is favorably applied to various kinds of linear and nonlinear problems. The method has been shown to solve effectively, easily and accurately a large class of linear and nonlinear problems.

Generally, one or two iterations may lead to high accurate solutions. This method is, in fact, a modification of the general Lagrange multiplier method [He, 2007], [Batiha B., 2008] into an iteration method, which is called correction functional. Generally speaking, the solution procedure of the VIM is very effective, straightforward and convenient. Several studies have been conducted to compare the VIM with other existing techniques, and it is shown by all that this method may give exact solutions faster than other methods, in which the convergence concept has been proved a substantial amount of research work. It is remarkable that the VIM gives rapidly convergent successive approximations of the exact solution if such a solution exists; otherwise, a few approximations can be used for numerical purposes, [Al-Jamal, 2009]. has been directed to the study of the VIM by many well-known researchers [Guo, 2013], [Momani, 2006].

This paper is organized as follows; in section 2 some basic and fundamental definitions of fractional calculus are presented for completeness purpose. In section 3, we describe the formulation as well as, the convergence of the variational iteration method for solving two-points boundary value problems and then some illustrative examples are given in section 4 .

\section{Basic Concepts}

In this section, basic definitions and fundamental concepts related to this paper will be introduced, including fractional order differentiation and integration in addition to the basic of elements of the VIM.

\section{Definition 1:}

Riemann-Liouville definition of fractional integral operator of order $\mathrm{q} \geq 0$ [Fang Li, 2012], for a continuous function $\mathrm{f}$ is defined as:

$$
{ }^{R L} I^{q} f(x)=\frac{1}{\Gamma(q)} \int_{0}^{x}(t-s)^{q-1} f(s) d s, q>0, x>0
$$


where $\Gamma$ is the well-known Euler's gamma function, defined by:

$\Gamma(\mathrm{x})=\int_{0}^{\mathrm{x}} \mathrm{e}^{-\mathrm{t}} \mathrm{t}^{\mathrm{x}-1} \mathrm{dt}, \mathrm{x}>0$

Some basic properties that are satisfied by Riemann-Liouville fractional order integration may be summarized for all $p, q \geq 0$ and $\gamma \geq-1$, as follows:

1. ${ }^{R L} I^{0} f(x)=f(x)$.

2. ${ }^{R L} I^{q} x^{p}=\frac{\Gamma(p+1)}{\Gamma(q+p+1)} x^{q+p}$

3. ${ }^{R L} I^{q} I^{p} f(x)={ }^{R L} I^{p ~ R L} I^{q} f(x)=$ ${ }^{R L}{ }_{I}{ }^{p+q} f(x)$.

\section{Definition 2:}

Caputo fractional order derivative of order $q \geq 0$ [Fang Li, 2012], [Murio, 2006] for a continuous function $\mathrm{f}$ is defined as follows:

${ }^{C} D^{q} f(x)=\left\{\begin{array}{c}\frac{1}{\Gamma(m-q)} \int_{0}^{x} \frac{f^{(m)}(\tau)}{(x-\tau)^{q+1-m}} d \tau, m-1<q \leq m \\ \frac{d^{(m)}}{d x^{(m)}} f(x), q=m\end{array}\right.$

The Caputo fractional order derivative satisfies the following properties:

1. ${ }^{\mathrm{C}} \mathrm{D}^{\mathrm{q}} \mathrm{c}=0$, where $\mathrm{c}$ is a constant.

2. ${ }^{\mathrm{C}} \mathrm{D}^{\mathrm{q}} \mathrm{x}^{\mathrm{p}}=0$, for $\mathrm{p} \leq \mathrm{q}-1, \mathrm{q}, \mathrm{p} \in \mathbb{R}^{+}$.

3. ${ }^{\mathrm{C}} \mathrm{D}^{\mathrm{q}} \mathrm{x}^{\mathrm{p}}=\frac{\Gamma(\mathrm{p}+1)}{\Gamma(\mathrm{p}-\mathrm{q}+1)} \mathrm{x}^{\mathrm{p}-\mathrm{q}}$, for $\mathrm{p}>\mathrm{q}-1$,

$\mathrm{q}, \mathrm{p} \in \mathbb{R}^{+}$.

4. ${ }^{C} D^{q R L} I^{q} f(x)=f(x)$.

5. ${ }^{R L} I^{q C} D^{q} f(x)=f(x)-\sum_{k=0}^{m-1} f^{(k)}\left(0^{+}\right) \frac{x^{k}}{k !}$, where $\mathrm{m}-1<\mathrm{q} \leq \mathrm{m}, \mathrm{m} \in \mathbb{N}$.

\section{Variational Iteration Method}

The basic idea of the VIM [He, 2007], [Elham, A., 2004] is to consider the following general non-linear equation given in operator form:

$\mathrm{L}(\mathrm{y}(\mathrm{x}))+\mathrm{N}(\mathrm{y}(\mathrm{x}))=\mathrm{g}(\mathrm{x}), \mathrm{x} \in[\mathrm{a}, \mathrm{b}]$

where $\mathrm{L}$ is a linear operator, $\mathrm{N}$ is a nonlinear operator and $\mathrm{g}$ is any given function which is called the non-homogeneous. Now rewrite eq. (5) as follows:

$\mathrm{L}(\mathrm{y}(\mathrm{x}))+\mathrm{N}(\mathrm{y}(\mathrm{x}))-\mathrm{g}(\mathrm{x})=0$

and let $\mathrm{y}_{\mathrm{n}}$ be the $\mathrm{n}^{\text {th }}$ approximate solution

of eq. (5), then:

$\mathrm{L}\left(\mathrm{y}_{\mathrm{n}}(\mathrm{x})\right)+\mathrm{N}\left(\mathrm{y}_{\mathrm{n}}(\mathrm{x})\right)-\mathrm{g}(\mathrm{x}) \neq 0$

the correction functional for eq.(5), is given by:

$$
\begin{aligned}
\mathrm{y}_{\mathrm{n}+1}(\mathrm{x})= & \mathrm{y}_{\mathrm{n}}(\mathrm{x})+\int_{0}^{\mathrm{x}} \lambda(\mathrm{s})\left\{\mathrm { L } \left(\mathrm{y}_{\mathrm{n}}(\mathrm{s})+\right.\right. \\
& \left.\mathrm{N}\left(\tilde{\mathrm{y}}_{\mathrm{n}}(\mathrm{s})\right)-\mathrm{g}(\mathrm{s})\right\} \mathrm{ds}
\end{aligned}
$$

where $\lambda$ is the general Lagrange multiplier which can be identified optimally via the variation theory, the subscript $\mathrm{n}$ denotes the $\mathrm{n}^{\text {th }}$ approximation of the solution $\mathrm{y}$ and $\tilde{y}_{\mathrm{n}}$ is considered as a restricted variation, i.e., $\delta \tilde{y}_{\mathrm{n}}=0$, [Batiha, 2008].

To find the $(n+1)^{\text {th }}$ iteration of the solution using the VIM, one must first determine the Lagrange multiplier $\lambda$ that will be identified optimally via integration by parts. Then the successive approximation $\mathrm{y}_{\mathrm{n}}(\mathrm{x}), \mathrm{n}=0,1, \ldots$; of the solution $\mathrm{y}(\mathrm{x})$ will be readily obtained upon using the obtained Lagrange multiplier and by using any selective initial guess function $\mathrm{y}_{0}(\mathrm{x})$.

The approximation of initial solution $\mathrm{y}_{0}$ may be selected to be any function that just satisfies at least the initial and boundary conditions with $\lambda$ pre-determined, then several approximations $\mathrm{y}_{\mathrm{n}}(\mathrm{x}), \mathrm{n}=1,2, \ldots$ will follows immediately, and consequently the exact solution may be arrived since one may prove that $\mathrm{y}(\mathrm{x})=\lim _{\mathrm{n} \rightarrow \infty} \mathrm{y}_{\mathrm{n}}(\mathrm{x})$. In other words, the correction functional for eq. (8) will give several approximations, and therefore the exact solution is obtained as the limit of the resulting successive approximations.

\section{Problem Formulation and the VIM for Solving BVP of Fractional Order}

The consider problem of this paper is to solve the following BVP of fractional order:

$$
\begin{array}{r}
{ }^{\mathrm{c}} \mathrm{D}^{\mathrm{q}} \mathrm{y}(\mathrm{x})=\mathrm{f}\left(\mathrm{x}, \mathrm{y}(\mathrm{x}),{ }^{\mathrm{c}} \mathrm{D}^{\mathrm{p}} \mathrm{y}(\mathrm{x})\right), 1<\mathrm{q} \leq \\
2,0<\mathrm{p} \leq 1, \mathrm{x} \in[\mathrm{a}, \mathrm{b}]
\end{array}
$$

where $\mathrm{f}$ is given continues function and the initial condition are considered of two-points, as follows:

$y(a)=y_{a}, y(b)=y_{b}$

Now, the formulation of the VIM of problem (9)-(10) is given in the next theorem:

\section{Theorem 1:}

Consider the two-points BVP (9)-(10) of fractional order, then the sequence of iterative solutions using the VIM is given by: 


$$
\begin{aligned}
& y_{n+1}(x)=y_{n}(x)+{ }^{R L} I^{q}(x-s) \\
& \quad\left[{ }^{c} D^{q} y(s)-f\left(s, y(s),{ }^{c} D^{p} y(s)\right)\right]
\end{aligned}
$$

for all $\mathrm{n}=0,1, \ldots$

Proof:

Since from eq.(11):

$$
\begin{gathered}
{ }^{\mathrm{c}} \mathrm{D}^{\mathrm{q}} \mathrm{y}(\mathrm{x})=\mathrm{f}\left(\mathrm{x}, \mathrm{y}(\mathrm{x}),{ }^{\mathrm{c}} \mathrm{D}^{\mathrm{p}} \mathrm{y}(\mathrm{x})\right), 1<q \leq \\
2,0<p \leq 1, \mathrm{x} \in[\mathrm{a}, \mathrm{b}]
\end{gathered}
$$

which may be rewritten equivalently as:

${ }^{c} D^{q} y(x)-f\left(x, y(x),{ }^{c} D^{p} y(x)\right)=0$

Therefore, the correction functional using the VIM is given by:

$\mathrm{y}_{\mathrm{n}+1}(\mathrm{x})=\mathrm{y}_{\mathrm{n}}(\mathrm{x})+{ }^{\mathrm{RL}} \mathrm{I}^{\mathrm{q}}\left[\lambda(\mathrm{x}, \mathrm{s})\left\{{ }^{\mathrm{c}} \mathrm{D}^{\mathrm{q}} \mathrm{y}_{\mathrm{n}}(\mathrm{s})-\right.\right.$

$$
\left.\left.\mathrm{f}\left(\mathrm{s}, \tilde{y}_{\mathrm{n}}(\mathrm{s}),{ }^{\mathrm{c}} \mathrm{D}^{\mathrm{p}} \mathrm{y}_{\mathrm{n}}(\mathrm{s})\right)\right\}\right]
$$

and in order to find $\lambda$, approximate ${ }^{\mathrm{Re}} \mathrm{I}^{\mathrm{q}}$ by a single integral and approximate ${ }^{\mathrm{c}} \mathrm{D}^{\mathrm{q}} \mathrm{y}$ by $\mathrm{y}^{\prime \prime}$, then eq.(12) will be reduced to:

$$
\begin{array}{r}
\mathrm{y}_{\mathrm{n}+1}(\mathrm{x})=\mathrm{y}_{\mathrm{n}}(\mathrm{x})+\int_{a}^{x}\left[\lambda ( \mathrm { x } , \mathrm { s } ) \left[y_{n}^{\prime \prime}(\mathrm{s})-\right.\right. \\
\mathrm{f}\left(\mathrm{s}, \tilde{y}_{\mathrm{n}}(\mathrm{s}),{ }^{c} \mathrm{D}^{\mathrm{p}} \mathrm{y}_{\mathrm{n}}(\mathrm{s})\right] \mathrm{ds}
\end{array}
$$

by taking the first variation of eq.(13) with respect to $\mathrm{y}_{\mathrm{n}}$ and taking thus $\delta \mathrm{y}_{\mathrm{n}}(a)=$ $\delta y_{n}^{\prime}(a)=0$ yields to:

$$
\begin{aligned}
\delta y_{n+1}(x)= & \delta y_{n}(x)+\delta \int_{a}^{x} \lambda(x, s)\left[y_{n}^{\prime \prime}(s)-\right. \\
& f\left(s, \tilde{y}_{n}(s),{ }^{c} D^{p} y_{n}(s)\right] d s
\end{aligned}
$$

wherey $_{n}$ is considered as a restricted variation and hence:

$\delta y_{n+1}(x)=\delta y_{n}(x)+\int_{a}^{x} \lambda(x, s) \delta y_{n}^{\prime \prime}(s) d s$

carrying the integration by parts twice, then eq.(14) will be

$$
\begin{aligned}
\delta y_{\mathrm{n}+1}(\mathrm{x})= & \delta \mathrm{y}_{\mathrm{n}}(\mathrm{x})+\left.\lambda \delta \mathrm{y}_{\mathrm{n}}^{\prime}(\mathrm{s})\right|_{\mathrm{a}} ^{\mathrm{x}}- \\
& \left.\lambda^{\prime} \delta \mathrm{y}_{\mathrm{n}}(\mathrm{s})\right|_{\mathrm{a}} ^{\mathrm{x}}+\int_{\mathrm{a}}^{\mathrm{x}} \lambda^{\prime \prime}(\mathrm{x}, \mathrm{s}) \delta \mathrm{y}_{\mathrm{n}}(\mathrm{s}) \mathrm{ds} \\
= & \left(1-\lambda^{\prime}\right) \delta \mathrm{y}_{\mathrm{n}}+\lambda \delta \mathrm{y}_{\mathrm{n}}^{\prime}(\mathrm{x})+ \\
& \int_{\mathrm{a}}^{\mathrm{x}} \lambda^{\prime \prime}(\mathrm{x}, \mathrm{s}) \delta \mathrm{y}_{\mathrm{n}}(\mathrm{s}) \mathrm{ds}
\end{aligned}
$$

and from the theory of calculus of variation, and since $\delta y_{n}$ is arbitrary, then the following Euler equation is obtained.

$\lambda^{\prime \prime}(\mathrm{x}, \mathrm{s})=0$

With stationary conditions:

$$
1-\left.\lambda^{\prime}(\mathrm{x}, \mathrm{s})\right|_{\mathrm{s}=\mathrm{x}}=0,\left.\lambda(\mathrm{x}, \mathrm{s})\right|_{\mathrm{s}=\mathrm{x}}=
$$$$
0 \ldots(3.12)(16)
$$

Solving (15)-(16) will give the solution

$\lambda(\mathrm{x}, \mathrm{s})=\mathrm{x}-\mathrm{s}$

Thus the correction functional will reads as follows

$$
\begin{aligned}
& y_{n+1}(x)=y_{n}(x)+{ }^{R L} I^{q}[(x-s) \\
& \left({ }^{c} D^{q} y_{n}(s)-f\left(s, y(s),{ }^{c} D^{p} y(s)\right)\right] .
\end{aligned}
$$

\section{Convergence Analysis}

In the present section, the convergence of the sequence of approximate iterative solutions of problem(9)-(10) using the VIM for solving two-point boundary value problems of fractional order will be proved (for cases 1 and 3). The main idea of the proof is based upon evaluating the upper bound of the error term between the exact and approximate solution of problem (9)-(10) which is proved to be tends to zero as $\mathrm{n}$ tends to $\infty$.

\section{Theorem 2:}

Let $C^{2}[0,1]$ be the exact and approximate solution of the BVP of fractional order: ${ }^{\mathrm{c}} \mathrm{D}^{\mathrm{q}} \mathrm{y}(\mathrm{x})=\mathrm{f}\left(\mathrm{x}, \mathrm{y}(\mathrm{x}),{ }^{\mathrm{c}} \mathrm{D}^{\mathrm{p}} \mathrm{y}(\mathrm{x})\right), 1<q \leq$ $2,0<p \leq 1, \mathrm{x} \in[\mathrm{a}, \mathrm{b}] \ldots(16)$ and $\left\|{ }^{\mathrm{c}} \mathrm{D}^{\mathrm{q}} \mathrm{y}\right\| \leq\|y\|$, if $\mathrm{E}_{\mathrm{n}}(\mathrm{x})=\mathrm{y}_{\mathrm{n}}(\mathrm{x})-$ $\mathrm{y}(\mathrm{x})$ and $\mathrm{f}$ satisfies Lipschitz condition with constant $\mathrm{L}$, such that $\mathrm{L}<\frac{\Gamma(\mathrm{q})}{1+c}$, then the sequence of approximate solutions $\left\{y_{n}\right\}, n=0,1, \ldots$; converges to the exact solution.

\section{Proof:}

Since the VIM is given by:

$$
\begin{array}{r}
y_{n+1}=y_{n}+{ }^{R L} I^{q}\left[(x-s){ }^{c} D^{q} y_{n}-\right. \\
\left.f\left(s, y_{n}(s),{ }^{c} D^{p} y_{n}(s)\right)\right]
\end{array}
$$

and $y$ is the exact solution, hence:

$\mathrm{y}=\mathrm{y}+{ }^{R L} \mathrm{I}^{\mathrm{q}}\left[(\mathrm{x}-\mathrm{s}){ }^{\mathrm{c}} \mathrm{D}^{\mathrm{q}} \mathrm{y}-\mathrm{f}\left(\mathrm{s}, \mathrm{y}(\mathrm{s}),{ }^{\mathrm{c}} \mathrm{D}^{\mathrm{p}} \mathrm{y}(\mathrm{s})\right)\right]$

subtraction eq.(17) from eq. (18) will yields to:

$$
\begin{aligned}
y_{n+1}-y= & y_{n}-y+{ }^{R L} I^{q}[(x-s) \\
& \left({ }^{c} D^{q} y_{n}-{ }^{c} D^{q} y-\right. \\
& \left(f\left(s, y_{n}(s),{ }^{c} D^{p} y_{n}(s)\right)-\right. \\
& \left.f\left(s, y(s),{ }^{c} D^{p} y(s)\right)\right]
\end{aligned}
$$

i.e.,

$$
\begin{aligned}
E_{n+1}(x)= & E_{n}(x)+{ }^{R L} I^{q}\left[( x - s ) \left({ }^{c} D^{q} E_{n}-\right.\right. \\
& \left(f \left(s, y_{n}(s),{ }^{c} D^{p} y_{n}(s)-\right.\right. \\
& \left.f\left(s, y(s),{ }^{c} D^{p} y(s)\right)\right] \\
= & E_{n}+{ }^{R L} I^{q}(x-s){ }^{c} D^{q} E_{n}- \\
& R L I^{q}(x-s)\left[f \left(s, y_{n}(s),{ }^{c} D^{p} y_{n}(s)\right.\right. \\
- & \left.f\left(s, y(s),{ }^{c} D^{p} y(s)\right)\right]
\end{aligned}
$$




$$
\begin{aligned}
= & E_{n}-{ }^{R L} I^{q}(s-x){ }^{c} D^{q} E_{n}- \\
& R L I^{q}(x-s)\left[f \left(s, y_{n}(s),{ }^{c} D^{p} y_{n}(s)-\right.\right. \\
& \left.f\left(s, y(s),{ }^{c} D^{p} y(s)\right)\right]
\end{aligned}
$$

we may suppose that the interval $x \in[a, b]$ may be scaled to $x \in[0,1]$ and hence $\sup |s-\mathrm{x}|<1$ therefore

$$
\begin{aligned}
& E_{n+1}(x) \leq E_{n}-E_{n}+E_{n}(0)-{ }^{R L} I^{q}(x- \\
&s)\left(f \left(s, y_{n}(s),{ }^{c} D^{p} y_{n}(s)-\right.\right. \\
& f\left(s, y(s),{ }^{c} D^{p} y(s)\right)
\end{aligned}
$$

with $E_{n}(0)=0$. and hence using the definition of ${ }^{\mathrm{RL}} \mathrm{I}^{\mathrm{q}}$, we have:

$$
\begin{aligned}
& \mathrm{E}_{\mathrm{n}+1}(\mathrm{x})= \\
& \frac{-1}{\Gamma(\mathrm{q})} \int_{0}^{\mathrm{x}}(\mathrm{x}-\mathrm{s})^{\mathrm{q}-1}\left[\mathrm { f } \left(\mathrm{~s}, \mathrm{y}_{\mathrm{n}}(\mathrm{s}),{ }^{\mathrm{c}} \mathrm{D}^{\mathrm{p}} \mathrm{y}(\mathrm{s})-\right.\right. \\
& \mathrm{f}\left(\mathrm{s}, \mathrm{y}_{\mathrm{n}}(\mathrm{s}),{ }^{\mathrm{c}} \mathrm{D}^{\mathrm{p}} \mathrm{y}(\mathrm{s})\right] \mathrm{ds}
\end{aligned}
$$

Now, take the supremum norm to the both side of eq. (19), we get:

$$
\begin{gathered}
\left\|E_{n+1}(x)\right\| \leq \frac{1}{\Gamma(q)} \int_{0}^{x}\left\|(x-s)^{q-1}\right\| \\
\| f\left(s, y_{n}(s),{ }^{c} D^{p} y_{n}(s)-\right. \\
f\left(s, y(s),{ }^{c} D^{p} y(s) \| d s\right. \\
\leq \frac{1}{\Gamma(q)} \int_{0}^{x}\left(\left\|E_{n}\right\|+\left\|{ }^{c} D^{q} E_{n}\right\|\right) d s \\
\leq \frac{1}{\Gamma(q)} \int_{0}^{x}\left(\left\|E_{n}\right\|+c\left\|E_{n}\right\|\right) d s \\
=\frac{L(1+c)}{\Gamma(q)} \int_{0}^{x}\left\|E_{n}(s)\right\| d s, n=0,1, \ldots
\end{gathered}
$$

If $\mathrm{n}=0$, then:

$$
\begin{aligned}
& \left\|E_{1}\right\| \leq \frac{L(1+c)}{\Gamma(q)} \int_{0}^{x}\left\|E_{0}\right\| d s=\frac{L(1+c)}{\Gamma(q)}\left\|E_{0}\right\| x \\
& \begin{aligned}
\left\|E_{2}\right\| & \leq \frac{L(1+c)}{\Gamma(q)} \int_{0}^{x}\left\|E_{1}\right\| d s \\
& \leq \frac{L(1+c)}{\Gamma(q)} \int_{0}^{x} \frac{L(1+c)}{\Gamma(q)}\left\|E_{0}\right\| d s \\
& \leq \frac{L(1+c)}{\Gamma(q)} \int_{0}^{x} \frac{L(1+c)}{\Gamma(q)}\left\|E_{0}\right\| d s \\
& =\frac{L^{2}(1+c)^{2}}{\Gamma^{2}(q)}\left\|E_{0}\right\| \frac{x^{2}}{2}
\end{aligned}
\end{aligned}
$$

Hence, in general, using mathematical induction, we have:

$\left\|E_{n}\right\| \leq\left(\frac{L(1+c)}{\Gamma(q)}\right)^{n}\left\|E_{0}\right\| \frac{x^{n}}{n !}$

Since $\mathrm{L}<\frac{\Gamma(\mathrm{q})}{1+c}$ and therefore as $\mathrm{n} \rightarrow$

$\infty$, we have $\left(\frac{\mathrm{L}(1+\mathrm{c})}{\Gamma(\mathrm{q})}\right)^{\mathrm{n}} \rightarrow 0 \quad$ and $\quad \frac{1}{\mathrm{n} !} \rightarrow$

0 and therefore $\left\|E_{n}(s)\right\|_{\infty} \rightarrow$

0 , i. e. , $y_{n}(x) \rightarrow y(x)$.

\section{Numerical Simulation}

In this section Numerical simulation for two illustrative examples, which are for linear and nonlinear fractional order BVPs:

\section{Example 1:}

Consider the linear fractional order BVP

${ }^{\mathrm{c}} \mathrm{D}^{1.5} \mathrm{y}+\mathrm{y}=4.513516 \mathrm{x}^{0.5}-\frac{0.282094}{\mathrm{x}^{1.5}}+$

$$
1+2 x^{2}, x \in[0,1]
$$

With two-points boundary conditions $y(0)=1, y(1)=3$

For comparison purpose the exact solution is given by:

$y(x)=1+2 x^{2}$

According to the VIM, we derive a correction functional as follows:

$$
\begin{aligned}
y_{n+1}(x)= & y_{n}(x)+{ }^{R L} I^{1.5}(s-x)\left[{ }^{c} D^{1.5} y_{n}+\right. \\
& y_{n}-\left(4.513516 x^{0.5}-\frac{0.282094}{x^{1.5}}+\right. \\
& \left.\left.1+2 x^{2}\right)\right], x \in[0,1]
\end{aligned}
$$

Now, we begin with an arbitrary initial approximation:

$\mathrm{y}_{0}(\mathrm{x})=\mathrm{A}+\mathrm{Bx}$

where $\mathrm{A}$ and $\mathrm{B}$ are constants to be determined. By VIM (30) we have:

$$
\begin{aligned}
\mathrm{y}_{1}(\mathrm{x})= & \mathrm{y}_{0}(\mathrm{x})+{ }^{R L} \mathrm{I}^{1.5}(\mathrm{~s}-\mathrm{x}){ }^{\mathrm{c}} \mathrm{D}^{1.5} \mathrm{y}_{0}(\mathrm{~s})+ \\
& \frac{1}{2} \mathrm{y}_{0}(\mathrm{~s})-\left(4.513516 \mathrm{x}^{\frac{3}{2}}-\right. \\
& \left.\left.\frac{0.282094}{\mathrm{x}^{1.5}}+1-2 \mathrm{x}^{2}\right)\right\} \\
= & \mathrm{A}+\mathrm{Bx}+{ }^{\mathrm{RL}} \mathrm{I}^{1.5}(\mathrm{~s}-\mathrm{x})^{\mathrm{c}} \mathrm{D}^{1.5}(\mathrm{~A}+ \\
& \mathrm{Bx})+\frac{1}{2}(\mathrm{~A}+\mathrm{Bx})- \\
& \left(4.513516 \mathrm{x}^{\frac{3}{2}}-\frac{0.282094}{\mathrm{x}^{1.5}}+1-\right. \\
& \left.\left.2 \mathrm{x}^{2}\right)\right\}
\end{aligned}
$$

By imposing the boundary conditions at $\mathrm{x}=$ 0 and $\mathrm{x}=1$ yields $\mathrm{A}=1$ and $\mathrm{B}=-0.4694032$.

Now by using computer programs written in Mathcad 14the following results for $\mathrm{y}_{1}(\mathrm{x})$ and $\mathrm{y}_{2}(\mathrm{x})$ and $\mathrm{y}_{3}(\mathrm{x})$ are obtained. In table (1) comparison between the exact and approximate solution of the BVP (21). 
Table (1)

Exact and approximation solutions of example 1

\begin{tabular}{|c|c|c|c|c|}
\hline \hline $\boldsymbol{x}$ & $\boldsymbol{y}_{\boldsymbol{e}}(\boldsymbol{x})$ & $\boldsymbol{y}_{\mathbf{1}}(\boldsymbol{x})$ & $\boldsymbol{y}_{\mathbf{2}}(\boldsymbol{x})$ & $\boldsymbol{y}_{\mathbf{3}}(\boldsymbol{x})$ \\
\hline \hline 0 & 1 & 1 & 1 & 1 \\
\hline 0.2 & 1.08 & 1.058 & 1.069 & 1.077 \\
\hline 0.4 & 1.32 & 1.299 & 1.285 & 1.315 \\
\hline 0.6 & 1.72 & 1.613 & 1.657 & 1.718 \\
\hline 0.8 & 2.28 & 2.246 & 2.279 & 2.281 \\
\hline 1 & 3 & 3 & 3 & 3 \\
\hline
\end{tabular}

\section{Example 2:} BVP:

Consider the nonlinear fractional order

$$
\begin{aligned}
{ }^{\mathrm{c}} \mathrm{D}^{1.5} \mathrm{y}= & \mathrm{y}^{2}+{ }^{\mathrm{c}} \mathrm{D}^{1 / 4} \mathrm{y}+\left(4.513516 \mathrm{x}^{0.5}-\right. \\
& \frac{0.2820947}{\mathrm{x}^{1.5}}-4 \mathrm{x}^{2}-4 \mathrm{x}^{4}-\frac{1}{\mathrm{x}^{\frac{1}{4}} \Gamma\left(\frac{3}{4}\right)}- \\
& \left.\frac{64 \mathrm{x}^{\frac{7}{4}}}{5 \Gamma\left(\frac{3}{4}\right)}-1\right), \mathrm{x} \in[0,1]
\end{aligned}
$$

with two-points boundary condition $\mathrm{y}(0)=1, \mathrm{y}(1)=3$.

For comparison purpose, the exact solution is given by:

$\mathrm{y}(\mathrm{x})=1+2 \mathrm{x}^{2}$

According to the VIM we derive a correction functional as follows:

$$
\begin{aligned}
\mathrm{y}_{\mathrm{n}+1}(\mathrm{x})= & \mathrm{y}_{\mathrm{n}}(\mathrm{x})+{ }^{\mathrm{RL}} \mathrm{I}^{1.5} \lambda\left\{{ }^{\mathrm{c}} \mathrm{D}^{1.5} \mathrm{y}_{\mathrm{n}}-\right. \\
& \mathrm{y}_{\mathrm{n}}{ }^{2}-{ }^{\mathrm{c}} \mathrm{D}^{\frac{1}{4}} \mathrm{y}-\left[4.513516 \mathrm{x}^{0.5}-\right. \\
& \frac{0.2820947}{\mathrm{x}^{1.5}}-4 \mathrm{x}^{2}-4 \mathrm{x}^{4}-\frac{1}{\mathrm{x}^{\frac{1}{4}} \Gamma\left(\frac{3}{4}\right)}- \\
& \left.\left.\frac{64 \mathrm{x}^{\frac{7}{4}}}{5 \Gamma\left(\frac{3}{4}\right)}-1\right]\right\}
\end{aligned}
$$

Now, we begin with an arbitrary initial approximation:

$\mathrm{y}_{0}(\mathrm{x})=\mathrm{A}+\mathrm{Bx}$

where $\mathrm{A}$ and $\mathrm{B}$ are constants to be determined. By the VIM (32), we have:

$$
\begin{aligned}
\mathrm{y}_{1}(\mathrm{x})= & \mathrm{y}_{0}(\mathrm{x})+{ }^{\mathrm{RL}} \mathrm{I}^{1.5} \lambda\left\{{ }^{\mathrm{c}} \mathrm{D}^{1.5} \mathrm{y}_{0}-\right. \\
& \mathrm{y}_{0}{ }^{2}-{ }^{\mathrm{c}} \mathrm{D}^{\frac{1}{4}} \mathrm{y}-\left[4.513516 \mathrm{x}^{0.5}-\right. \\
& \frac{0.2820947}{\mathrm{x}^{1.5}}-4 \mathrm{x}^{2}-4 \mathrm{x}^{4}-\frac{1}{\mathrm{x}^{\frac{1}{4}} \Gamma\left(\frac{3}{4}\right)}- \\
& \left.\left.\frac{64 \mathrm{x}^{\frac{7}{4}}}{5 \Gamma\left(\frac{3}{4}\right)}-1\right]\right\} \\
= & \mathrm{A}+\mathrm{Bx}+{ }^{\mathrm{RL}} \mathrm{I}^{1.5} \lambda\left\{{ }^{\mathrm{c}} \mathrm{D}^{1.5}(\mathrm{~A}+\right. \\
& \mathrm{Bx})-(\mathrm{A}+\mathrm{Bx})^{2}-{ }^{\mathrm{c}} \mathrm{D}^{\frac{1}{4}}(\mathrm{~A}+ \\
& \mathrm{Bx})-\left[4.513516 \mathrm{x}^{0.5}-\right. \\
& \frac{0.2820947}{\mathrm{x}^{1.5}}-4 \mathrm{x}^{2}-4 \mathrm{x}^{4}-\frac{1}{\mathrm{x}^{\frac{1}{4}} \Gamma\left(\frac{3}{4}\right)}- \\
& \left.\left.\frac{64 \mathrm{x}^{\frac{7}{4}}}{5 \Gamma\left(\frac{3}{4}\right)}-1\right]\right\}
\end{aligned}
$$

By imposing the boundary conditions at $\mathrm{x}=0$ and $\mathrm{x}=1$ yields $\mathrm{A}=1$ and $\mathrm{B}=$ -0.058927 .

Now by using computer programs written in Mathcad 14, the following results for $\mathrm{y}_{1}(\mathrm{x})$ and, $\mathrm{y}_{2}(\mathrm{x})$ and $\mathrm{y}_{3}(\mathrm{x})$ are obtained. In table (2) comparison between the exact and approximate solution of the BVP (31).

Table (2)

Exact and approximation solutions of example 2

\begin{tabular}{|c|c|c|c|c|}
\hline $\boldsymbol{x}$ & $\boldsymbol{y}_{\boldsymbol{e}}(\boldsymbol{x})$ & $\boldsymbol{y}_{\mathbf{1}}(\boldsymbol{x})$ & $\boldsymbol{y}_{\mathbf{2}}(\boldsymbol{x})$ & $\boldsymbol{y}_{\mathbf{3}}(\boldsymbol{x})$ \\
\hline \hline 0 & 1 & 1 & 1 & 1 \\
\hline 0.2 & 1.08 & 1.044 & 1.045 & 1.074 \\
\hline 0.4 & 1.32 & 1.225 & 1.257 & 1.291 \\
\hline 0.6 & 1.72 & 1.597 & 1.681 & 1.718 \\
\hline 0.8 & 2.28 & 2.236 & 2.253 & 2.282 \\
\hline 1 & 3 & 3 & 3 & 3 \\
\hline
\end{tabular}




\section{Remark 1:}

It is clear that as $\mathrm{n} \longrightarrow \infty$, the sequence of iterated solutions will converge to the exact solution $\mathrm{y}(\mathrm{x})=1+2 \mathrm{x}^{2}$.

\section{Conclusions}

The VIM, as it is known, is a very accurate method, which may give the exact solution in a few steps, but in some cases it requires more calculations that will add some difficulties to the problem under consideration.

\section{References}

[1] Al-Jamal M. F. and Rawashdeh E. A., "The Approximate Solution of Fractional Integro-Differential Equations", Journal Contemp. Math. Sciences, Vol.4, No.22, pp. 1067-1078, 2009.

[2] Batiha B., Noorani M. S. and Hashim I., "Numerical Solutions of The Nonlinear Integro-differential Equations", Journal of Open Problems Compt. Math., Vol.1, No.1, pp. 34-41, 2008.

[3] Elham S., J. Hossein, A. Merich, Revised Variational Iteration Method for Solving System of Ordinary Differential Equations, an international Journal of Applications and Applied Mathematics, Special Issue No.1, 2010, 110-121.

[4] Fang Li, J. Liang and H. K. Xu, Journal of Mathematical Analysis and Applications 391(2), 510-525 (2012).

[5] Guo C., B. Dumitru, New Application of the Variational Iteration Method form Differential Equations to q-Fractional Difference Equations, Spring Open Journal, 2013, 1-16.

[6] He J. H., "The Variational Iteration Method: Reliable, Efficient and Promising", An International Journal, Computers and Mathematics with Applications, 54, pp. 879-880, 2007.

[7] He J. H., Variational iteration method for ordinary differential systems, Appl. Math. Comput. 118 (2-3) (2000).

[8] He J. H., Variational principles for some nonlinear partial differential equations with variable coefficients, Chaos, Solitons\& Fractals 19 (2004) 847-851.

[9] Kurulay M. and Secer A., "Variational Iteration Method for Solving Nonlinear Fractional Integro-Differential Equations", International Journal of
Computer Science and Emerging Technologies, Vol.2,pp. 18-20, 2011.

[10] Momani S., Jameel A. and Al-Azawi S., "Local and Global Uniqueness Theorems of Fractional Integro-Differential Equations Via Biharis and Grünwalls Inequalities", pp. 619-627, 2007.

[11] Murio D. A., On the stable numerical evaluation of Caputo fractional derivatives, Comput. Math. Appl. 51 (2006) 1539-1550. 